\title{
Microwave drying combined with magnetic stirring for quick analysis of oil content of fresh palm bunch
}

\author{
Rayakorn Nokkaew ${ }^{\mathrm{a}, \mathrm{b}}$, Vittaya Punsuvon ${ }^{\mathrm{a}, \mathrm{b}, *}$ \\ ${ }^{a}$ Department of Chemistry, Faculty of Science, Kasetsart University, Bangkok 10900 Thailand \\ b Centre of Excellence-Oil Palm, Kasetsart University, Bangkok 10900 Thailand
}

*Corresponding author, e-mail: fscivit@ku.ac.th

Received 19 Oct 2015

Accepted 21 Jun 2016

\begin{abstract}
The oil content of a fresh palm bunch (OCB) is a crucial factor in deciding the price of oil palm between the farmers and the oil palm mill owners. The mill owners usually use visual inspection and their experience to estimate the oil content, which does not provide an accurate estimate. The chemical extraction method (traditional oven drying combined with automated Soxhlet extraction) is the only method that is recommended as a standard for oil content analysis and practical use in Thailand. This method provides reliable results, but is time consuming. This study investigated the feasibility of a quick test to determine the oil and moisture content of the mesocarp using microwave drying to replace oven drying, and magnetic stirring to replace automated Soxhlet extraction. The results showed that the time required for the microwave drying technique was $6 \mathrm{~min}$, while the time for the oven method was $24 \mathrm{~h}$. Using magnetic stirring could also reduce the oil extraction time from $2 \mathrm{~h}$ to $10 \mathrm{~min}$ compared to automated Soxhlet extraction. Based on validation data, the method of microwave drying combined with magnetic stirring for OCB analysis gave a good correlation with the standard method and is thus recommended for a quick OCB analysis.
\end{abstract}

KEYWORDS: Soxhlet extraction, oven drying, palm fruit, mesocarp

\section{INTRODUCTION}

Oil palm (Elaeis guineensis Jacq.) is an important food and energy crop abundant in Southeast Asia. It originated from South Africa and was brought into Southeast Asia in $1884^{1}$. In August 2015, the US Department of Agriculture (USDA) reported that Malaysia and Indonesia were the world leaders in palm oil production and export, with Thailand being in the third position for oil palm production in Southeast $\mathrm{Asia}^{2}$. Palm oil comes in two types based on the part of the palm fruit from which the oil is extracted-crude palm oil from the mesocarp part and crude palm kernel oil from the palm kernel part (Fig. 1). Palm oil is used as a raw material not only in the food industry but also for fuel, especially biodiesel. The Thai Government has therefore tried to promote oil palm plantations with farmers by launching several policies to facilitate and create stakeholder activity. One of the important policies was to promote a fresh palm bunch trading system ${ }^{3}$.

At present, the price of fresh palm bunches is decided by the fraction of oil content per fresh palm bunch (OCB). The term oil content (OC) means the fraction of the weight of extracted oil per weight of dried mesocarp and the term OCB means the fraction of the total weight of extracted oil per total weight of a fresh palm bunch. Many researchers are trying to estimate the OCB and the OC quickly using different techniques as detailed below.

Near infrared spectroscopy (NIR) has been used to determine the OC in fresh palm fruits ${ }^{4,5}$. The OCB in fresh fruit palm bunches using an NIR technique has also been analysed ${ }^{6}$. An automatic machine vision procedure (digital image processing) has been used to study the OCB in fresh palm bunches ${ }^{7}$. In addition, the ultrasonic technique has been applied to the study of the OC in fresh palm fruits ${ }^{8}$. All these techniques however are not being used in Thai trade, as they predict the total oil content and not the OCB. The practical use for OCB analysis in Thailand has followed the standard method of Malaysia. The National Research Centre for Oil Palm of Malaysia has set the standard OCB method using two steps in the analysis once the mesocarp has been separated from the fresh palm fruit. The first step determines the moisture content (MC) in the fresh mesocarp. The MC is the weight loss obtained after drying at $100 \pm 5^{\circ} \mathrm{C}$ for $24 \mathrm{~h}$ using a hot-air oven. The second step determines the 


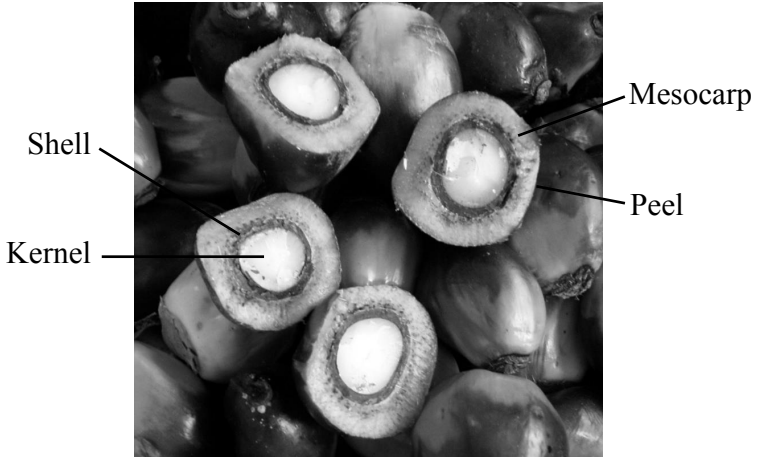

Fig. 1 Fresh oil palm fruit.

OC in the dried mesocarp using solvent extraction using an automated Soxhlet extractor for $2 \mathrm{~h}(14 \mathrm{~h}$ for conventional Soxhlet equipment). Then the obtained MC and OC are calculated and converted to the $\mathrm{OCB}^{9}$.

Microwave techniques in the drying process have been investigated in many studies. Microwave energy offers many advantages such as, less time, space saving, energy saving, and increased quality of the palm oil. Heating carried out using microwaves results from microwave energy generated by exposing the material to an electromagnetic field. Dipolar substances, especially water, which is the main ingredient in the oil palm fruit, can be thoroughly heated by dielectric heating using microwave irradiation ${ }^{10}$. Cheng et al used a microwave technique to dry palm fruits that completely removed the $\mathrm{MC}$ within $5 \mathrm{~min}^{11}$. In addition, the heating time using microwaves could increase the carotene and vitamin $\mathrm{E}$ content and reduce free fatty acids. These properties indicate good quality crude palm oil ${ }^{11,12}$. Solvent extraction has become the commonly used commercial technique to recover oil from oilseeds. Hexane solvent is preferred as it efficiently extracts the oilseed, leaving small residues in the seedcake. A single stage of solvent extraction is the main protocol and requires a long time for extraction. Nowadays, however, a short oil extraction time is needed, so multi-stage oil extraction has been used to reduce the time required for analysis. Achten et $\mathrm{al}^{13}$ and Nokkaew and Punsuvon ${ }^{14}$ used a multi-stage technique for complete oil recovery. They split the total extractant volume into several portions by carrying out three or more extraction steps.

The present study aims to develop a quick analysis of the OCB by omitting the use of the hot-air oven and automated Soxhlet extraction. We aim to determine the optimum time for mesocarp drying using microwaves and the optimum conditions of oil extraction from the dried mesocarp using magnetic stirring. Finally, we aim to validate our process to confirm its precision and accuracy by comparison with the OCB standard method ${ }^{9}$.

\section{MATERIALS AND METHODS}

\section{Materials}

Fresh oil palm bunches (FPB) of the Tenera species were obtained from the Oil Palm Technology Development for Local Commercial Biodiesel Industry in Newly Planted Area Project, Faculty of Agriculture, Kasetsart University, Thailand and used as raw material in this experiment. The age of the oil palm trees was about 4-5 years and the weight of each FPB was about 10-15 kg. The FPB were harvested and after collection were sent to the laboratory within 2 days for analysis.

\section{Sample preparation}

The FPB were weighed and divided into 3 zones (apical, equatorial, and basal) (Fig. 2). Then the FPB was chopped into spikelets (Fig. 3a) from the stalk, and palm fruits were further separated from each spikelet (Fig. 3b). Approximately $250 \mathrm{~g}$ (around 20-30 palm fruits) of representative palm fruits were selected for the OCB analysis. The mesocarp was scraped fully, leaving only the nut, and then weighed (Fig. 3c).

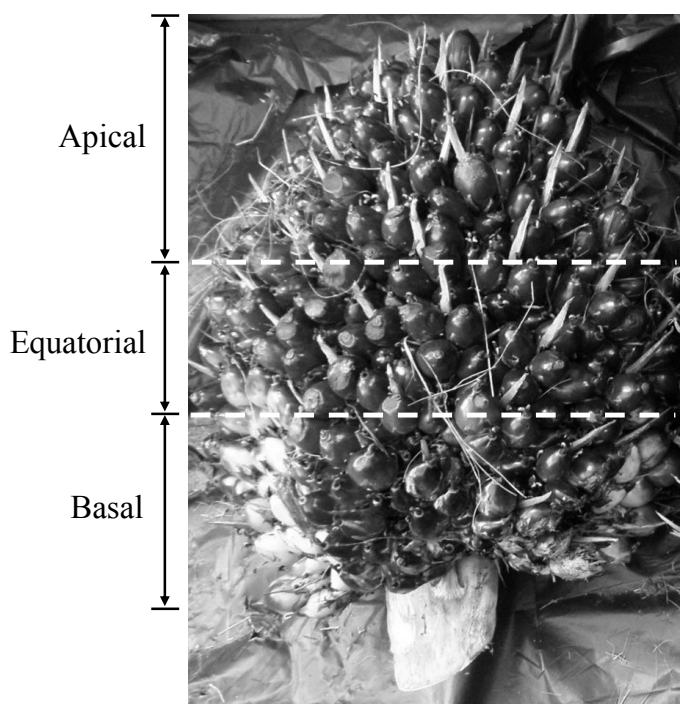

Fig. 2 FPB divided into 3 zones (apical zone, equatorial zone and basal zone). 

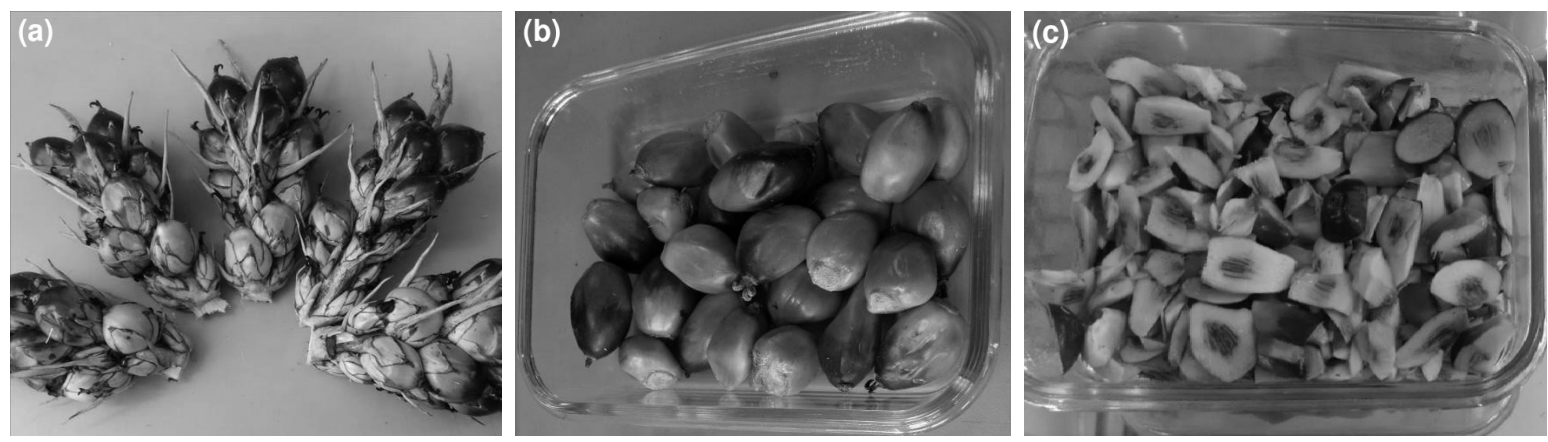

Fig. 3 Other parts separated from FPBs: (a) spikelets, (b) palm fruits, and (c) mesocarp.

\section{Optimum moisture content from microwave drying}

The scraped mesocarp was dried for different periods (0-10 $\mathrm{min})$ at $850 \mathrm{~W}$ and $2450 \mathrm{MHz}$ in a household microwave oven (Samsung ME109MSTD, Korea). The dried mesocarp from each drying time was weighed for MC determination based on the wet weight as $\mathrm{MC}=1-w_{\text {dried }} / w_{\text {fresh }}$, where $w_{\text {dried }}$ is the weight of dried mesocarp and $w_{\text {fresh }}$ is the weight of fresh mesocarp.

The experiments were performed in duplicate. The MC from the experiments and the MC from the standard method ${ }^{13}$ were then compared. In addition, the temperature of the mesocarp was measured after heating using an infrared thermometer gun.

\section{Optimum conditions to extract oil using magnetic stirring}

A sample of $3 \mathrm{~g}$ of dried mesocarp was used to study multi-stage oil extraction with magnetic stirring. Several parameters were considered to optimize OC recovery, namely the ratio of dried mesocarp to hexane solvent $(1: 5,1: 7$, and $1: 10 \mathrm{w} / \mathrm{v})$, the duration ( 5 and $10 \mathrm{~min}$ ), and the temperature $\left(35\right.$ and $55^{\circ} \mathrm{C}$ ). The stirring rate was kept constant following the work of Nokkaew and Punsuvon ${ }^{14}$ who found that the best stirring rate for oil extraction from Jatropha curcas meal was at $400 \mathrm{rpm}$. At each stage of oil extraction, a sample was collected by filtration and the solvent was removed from the oil using evaporation, followed by weighing for oil content determination as OC $=w_{\text {oil }} / w_{\text {dried }}$, where $w_{\text {oil }}$ is the weight of oil.

Re-oil extraction with fresh solvent at each stage was carried out until the weight of the extracted oil did not increase. The experiments were performed in duplicate. The OC from the experiments and the OC from the standard method ${ }^{9}$ were then com- pared.

Calculation of oil content per fresh palm bunch

OCB was obtained using the following equations:

$$
\begin{aligned}
w_{\text {dried,bunch }} & =w_{\text {fresh,bunch }}(1-\mathrm{MC}), \\
w_{\text {oil,bunch }} & =w_{\text {dried,bunch }}(\mathrm{OC}), \\
\mathrm{OCB} & =w_{\text {oil,bunch }} / w_{\text {bunch }},
\end{aligned}
$$

where $w_{\text {dried,bunch }}$ is the weight of dried mesocarp in each bunch, $w_{\text {fresh,bunch }}$ is the weight of fresh mesocarp in the bunch, $w_{\text {oil,bunch }}$ is the weight of total oil in the bunch, and $w_{\text {bunch }}$ is the weight of the bunch.

\section{Validation experiment}

A validation experiment was carried out between the new method and the standard method to compare the difference between the methods. The OCB analysis flow chart for both methods is represented in Fig. 4.

\section{RESULTS AND DISCUSSION \\ Optimum moisture content conditions for microwave drying}

The physical appearance of the dried mesocarp before and after microwave drying for various heating times $(0-10 \mathrm{~min})$ is shown in Fig. 5. As the exposure duration was extended, the weak orange colour of fresh mesocarp changed to orange, strong orange, yellow, brown, and black with a heating time of 0 , $2,4,6,8$, and $10 \mathrm{~min}$, respectively. The changed colour of the mesocarp indicated that microwave heating had an effect during drying and with increasing time, eventually burnt the dried mesocarp which was the same as reported by Cheng et $\mathrm{al}^{11}$. A heating time of 6 min resulted in effective drying as water was removed from the mesocarp due to the temperature being increased from $35^{\circ} \mathrm{C}$ (ambient 


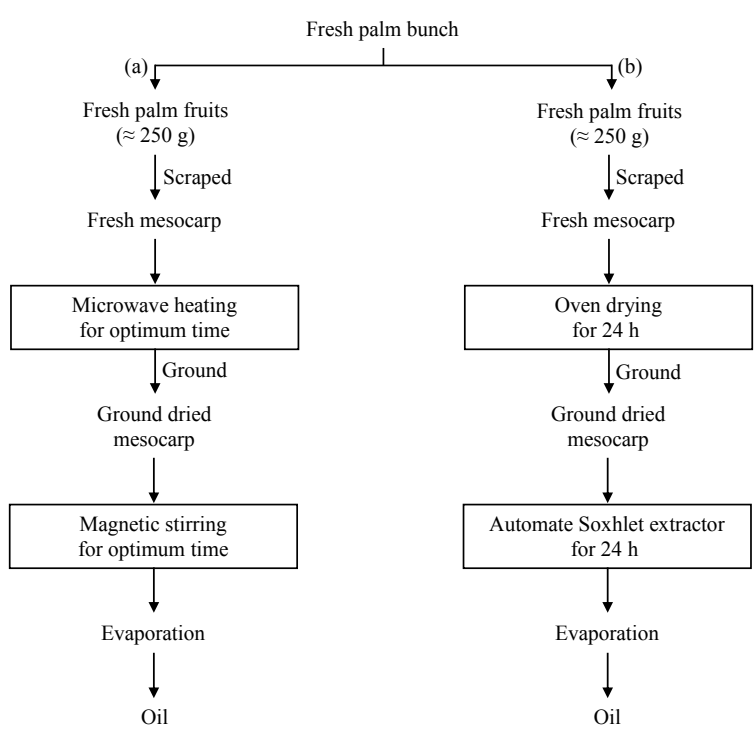

Fig. 4 Flow chart of OCB analysis for (a) new method and (b) standard method.

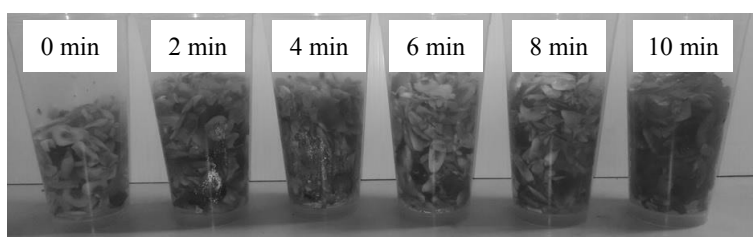

Fig. 5 Physical appearance of mesocarp after microwave heating for different periods.

temperature) to $100^{\circ} \mathrm{C}$. Fig. 6 shows the surface temperature of the mesocarp during microwave heating. The results showed that the temperature increase was directly proportional to the heating time. In addition, as the temperature increased, the oil in the mesocarp melted and dissolved the carotene pigment resulting in the colour of the dried mesocarp changing from weak orange to yellow. When the surface temperature of the dried mesocarp exceeded $100^{\circ} \mathrm{C}$ (Fig. 6), it caused burning and decomposition of the mesocarp and carotene pigment ${ }^{11}$.

\section{Effect of microwave heating on moisture content}

The initial MC in the mesocarp analysed using the standard method was $31 \%$ (w.b.). The effect of microwave drying compared with hot-air drying shown in Fig. 7 reveals that microwave drying for 6 min decreased the MC from $31 \%$ to $0 \%$, while conventional drying took at least $5 \mathrm{~h}$ to reach $0 \%$ MC. Currently, conventional drying takes $24 \mathrm{~h}$ to

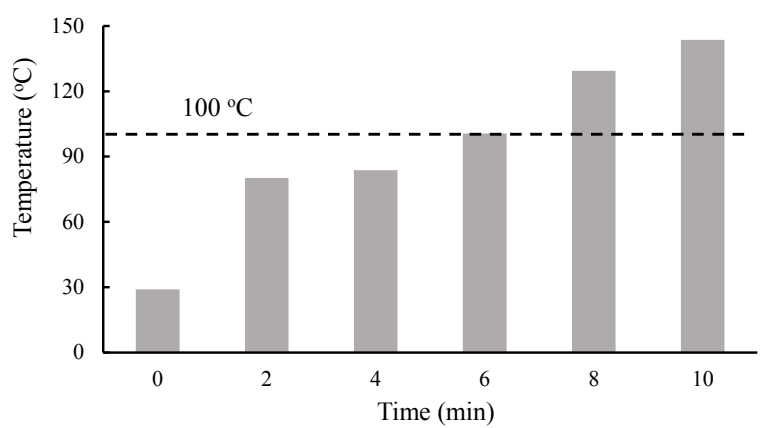

Fig. 6 Surface temperature change of dried mesocarp during microwave drying.
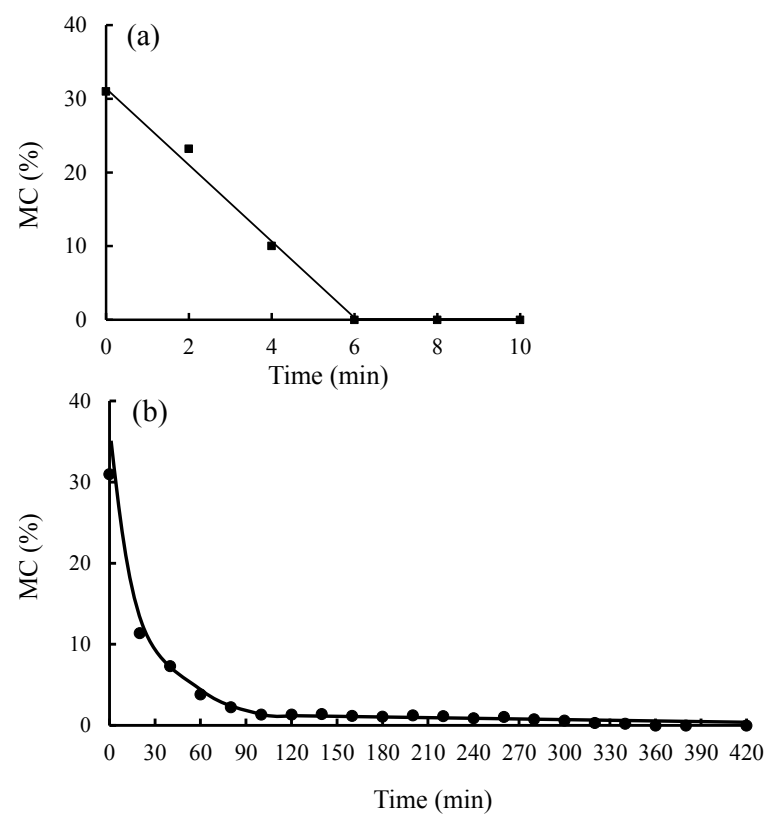

Fig. 7 Comparison of effect of (a) microwave drying and (b) hot air drying on MC over time.

ensure complete water removal from the sample; in practice, however, $5 \mathrm{~h}$ (300 $\mathrm{min})$ of drying time at $100^{\circ} \mathrm{C}$ was sufficient. Nur Khairunnisha et al ${ }^{15}$ explained that the microwave heating progress occurred from the inside to the outside of the material at a higher speed than in conventional drying which occurs from the outside to the inside of the material.

\section{Optimum conditions for oil extraction using multi-stage magnetic stirring}

The optimum conditions for microwave drying at 6 min were selected to remove water from the ground mesocarp. The OC analysis using $6 \mathrm{~min}$ of microwave drying followed with oil extraction using automated Soxhlet extraction for $2 \mathrm{~h}$ was conducted 

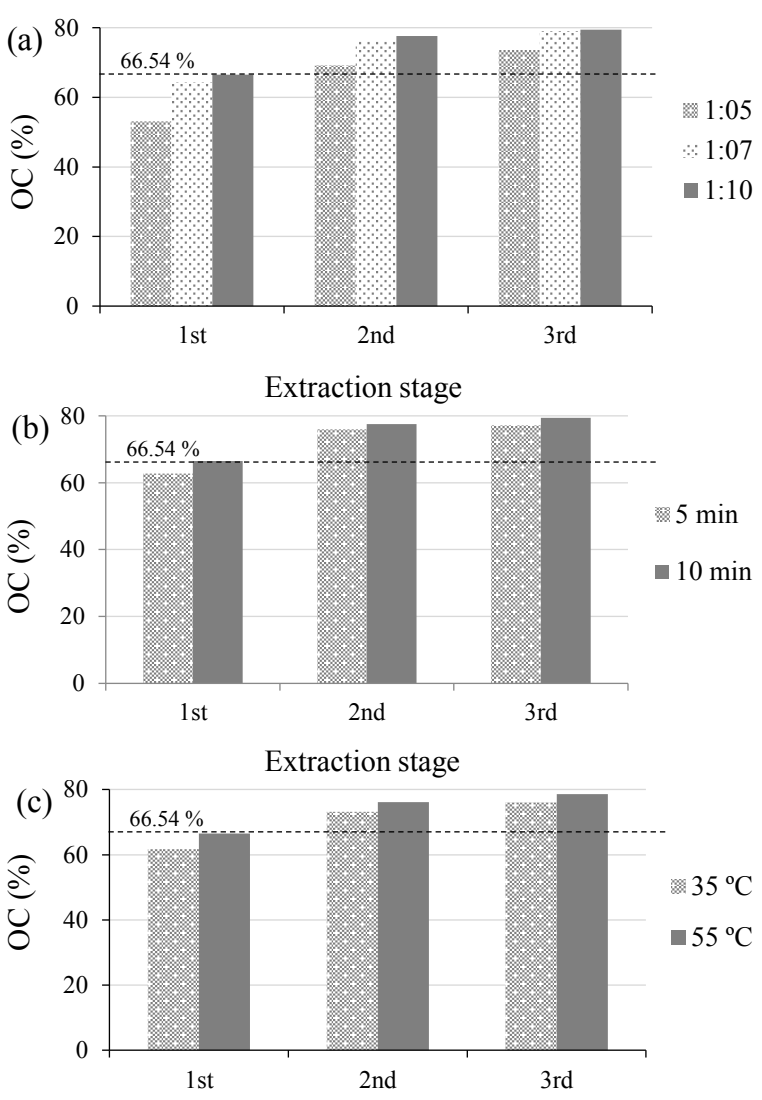

Extraction stage

Fig. 8 Oil extraction using multi-stage magnetic stirring at (a) different ratios of dried mesocarp to hexane solvent (oil extraction keeping constant temperature at $55^{\circ} \mathrm{C}$, $10 \mathrm{~min}$ duration time and stirring rate at $400 \mathrm{rpm}$ ); (b) different duration times (oil extraction keeping constant temperature at $55^{\circ} \mathrm{C}, 1: 10(\mathrm{w} / \mathrm{v})$ ratio of dried mesocarp to hexane and stirring rate at $400 \mathrm{rpm}$ ); (c) different temperatures (oil extraction keeping 1:10 (w/v) constant ratio of dried mesocarp to hexane, for $10 \mathrm{~min}$ duration time and stirring rate at $400 \mathrm{rpm}$ ).

as the reference method and produced a yield of $66 \%$ OC. The results of replacing the automated Soxhlet extraction with multi-stage magnetic stirring are shown in Fig. 8. The total OC is the sum of the $\mathrm{OC}$ for the current stage plus the former stages. For example, the total OC for the third stage was the total OC from all 3 stages. Given a target total OC of nearly $67 \%$, it can be seen that the first stage procedure already achieved this with a ratio of 1:10 of dried mesocarp to hexane, $10 \mathrm{~min}$ extraction, time and $55^{\circ} \mathrm{C}$ as shown in Fig. 8 a to Fig. 8 c, respectively. The optimum conditions produced $66 \%$ OC. The results shown in Fig. 8 also indicated that
Table 1 Validation test for OCB determination between the new method and the standard method.

\begin{tabular}{lccc}
\hline $\begin{array}{l}\text { Sample } \\
\text { no. }\end{array}$ & \multicolumn{2}{c}{ OCB (\%) } & $\begin{array}{c}\text { Error* } \\
\text { (\%) }\end{array}$ \\
\cline { 2 - 3 } & New method & Standard method & \\
\hline 1 & 19.34 & 19.42 & 0.43 \\
2 & 20.07 & 20.00 & 0.34 \\
3 & 20.00 & 19.99 & 0.04 \\
4 & 20.33 & 20.23 & 0.49 \\
5 & 26.59 & 26.43 & 0.63 \\
\hline
\end{tabular}

"Error $=\left|1-\mathrm{OCB}_{\text {new }} / \mathrm{OCB}_{\text {standard }}\right|$

multi-stage extraction with an increased hexane to dried mesocarp ratio had the greatest influence on oil extraction.

\section{Validation test for oil content per fresh palm bunch}

The validation test compared the new method (6 min of microwave drying + one stage of magnetic stirring) for OCB determination with the standard method. Five separate samples of fresh palm bunches were used as the raw material for OCB determination. The obtained results were compared and the difference between the two methods was determined. The results of the validation test in Table 1 show that the difference between methods was less than $1 \%$ which indicates that both methods produced a similar result. Thus the new method can be used to replace the conventional method for OCB determination.

\section{CONCLUSIONS}

The feasibility was examined of using microwave drying combined with magnetic stirring for the determination of the OCB in fresh palm bunches. The results revealed that this combination could reduce the operating time to $16 \mathrm{~min}$ instead of $26 \mathrm{~h}$ without any substantial difference in the OCB analysis when compared with the standard method. It can be concluded that this new method shows promise as a method to replace the non-scientific approach currently used in oil palm trading between farmers and mill owners in Thailand. In addition, this new method was not only reliable when compared with the standard method but also had a much faster analysis time.

Acknowledgements: The authors would like to thank the Research and Researcher for Industries-RRI for the researcher grant and the Faculty of Agriculture, Kasetsart University for raw materials support. We also would 
like to acknowledge the Centre of Excellence Oil Palm, Kasetsart University for partial support of this study.

\section{REFERENCES}

1. Lin SW (2002) Palm oil. In: Gunstone FD (ed) Vegetable Oils in Food Technology: Composition, Properties and Uses, 1st edn, Blackwell Publishing Ltd, Oxford, UK, pp 59-97.

2. United States Department of Agriculture (2015) Oil Seeds: World Markets and Trade, USDA, Washington, DC.

3. Thai Industrial Standards (1992) Standard for Edible Palm Oil, Industrial Standard TIS 288-2535, Ministry of Agriculture, Thailand, ISBN 974-6060399-5.

4. Kasemsumran S, Thanapase W, Punsuvon V, Ozaki Y (2012) A feasibility study on non-destructive determination of oil content in palm fruits by visiblenear infrared spectroscopy. $J$ Near Infrared Spectros 20, 687-94.

5. Rittiron R, Thanapatay D, Narongwongwattana S, Sridaw P, Penthisan P, Ngowsakul W (2012) Development of diode array near infrared (NIR) spectrometer for determination of oil and moisture content in oil palm fruit. Agr Sci J 43, 127-30.

6. Makky M, Soni P (2014) In situ quality assessment of intact oil palm fresh fruit bunches using rapid portable non-contact and non-destructive approach. $J$ Food Eng 120, 248-59.

7. Makky M, Soni P, Salokhe VM (2014) Automatic nondestructive quality inspection system for oil palm fruits. Int Agrophys 28, 319-29.

8. Suwannarat S, Khaorapapong T, Chongcheawchamnan M (2012) Prediction of oil content in fresh palm fruit based on an ultrasonic technique. Kasetsart $J$ (Nat Sci) 46, 318-24.

9. Mandal PK (2008) Bunch Analysis of Oil Palm, Technical Bulletin No 8, National Research Centre for Oil Palm, Pedavegi, India.

10. Umudee I, Chongcheawchamnan M, Kiatweerasakul M, Tongurai C (2013) Sterilization of oil fresh fruit using microwave technique. Int J Chem Eng Appl 4, 111-3.

11. Cheng SF, Nor L M, Chuah CH (2011) Microwave pretreatment: A clean and dry method for palm oil production. Ind Crop Prod 34, 967-71.

12. Nokkaew R, Punsuvon V (2014) Sterilization of oil palm fruits by microwave heating for replacing steam treatment in palm oil mill process. Adv Mater Res 1025-6, 470-5.

13. Achten WMJ, Verchot L, Franken YJ, Mathijs E, Singh VP, Aerts R, Muys B (2008) Jatropha bio-diesel production and use. Biomass Bioenerg 32, 1063-84.

14. Nokkaew R, Punsuvon V (2015) Multi-stage solvent extraction for high yield oil and animal feed production from toxic Jatropha curcas meal. Walailak $J$ Sci Tech 12, 299-310.
15. Nur Khairunnisha IP, Bakar ES, Azwa AN, Choo ACY (2014) Effect of combination oven and microwave heating in the resin semi-curing process on the physical properties of 'compreg' OPW. Biol Res 9, 4899-907. 